\title{
Lack of salidroside impact on selected cytochromes encoding genes transcription in the liver of ethanol induced rats
}

\author{
RADOSŁAW KUJAWSKI ${ }^{1 \oplus}$, MICHAŁ SZULC ${ }^{1}$, MARIA TOBOŁA ${ }^{1}$, MARCIN GRACZYK ${ }^{1}$, \\ KAMILA CZORA-POCZWARDOWSKA ${ }^{1 \oplus}$, JUSTYNA BARANIAK ${ }^{20}$, \\ MAŁGORZATA KANIA-DOBROWOLSKA ${ }^{2 \oplus}$, JULIA SŁYŃKO-KRZYŻOSTANIAK ${ }^{1 \oplus,}$ \\ ANNA KRAJEWSKA-PATAN ${ }^{3 \oplus}$, PRZEMYSŁAW Ł. MIKOŁAJCZAK ${ }^{1,2 \odot}$
}

\author{
${ }^{1}$ Department of Pharmacology \\ Poznan University of Medical Sciences \\ Rokietnicka 5a \\ 60-806 Poznań, Poland \\ ${ }^{2}$ Department of Pharmacology and Phytochemistry \\ Institute of Natural Fibres and Medicinal Plants National Research Institute \\ Kolejowa 2 \\ 62-064 Plewiska, Poland \\ ${ }^{3}$ Department of Breeding and Botany of Useful Plants \\ Institute of Natural Fibres and Medicinal Plants National Research Institute \\ Kolejowa 2 \\ 62-064 Plewiska, Poland \\ *corresponding author: radkuj@ump.edu.pl
}

\section{Summary}

Introduction: The molecular basis of in vivo metabolism of selected representatives of phenylethanoids in the presence of ethanol has not been fully elucidated.

Objective: The aim was to estimate a salidroside (Sal) metabolism in the liver tissue in rats with induced alcohol tolerance by assessing changes in the transcription of genes encoding cytochromes: CYP1A2, 2D2, 3A1, $2 \mathrm{C} 23$.

Methods: cDNA was synthesized from total RNA isolated from rat liver samples. mRNA level changes were evaluated using real-time PCR (qRT-PCR) technique.

Results: Ethanol caused a significant induction of the CYP1A2 and CYP2C23 genes transcription, and a decrease in the CYP3A1 mRNA level, predominantly without statistical significance. A statistically significant increase of the CYP1A2 mRNA level was observed in the group receiving only Sal ( $4.5 \mathrm{mg} / \mathrm{kg}$ b.w.; p.o.) $(p<0.01)$.

Conclusions: There was no unequivocal effect of salidroside on the transcription of investigated cytochrome genes in the liver of rats with induced alcohol tolerance. 


\section{Key words: salidroside, Rhodiola rosea, Rhodiola kirilowii, alcohol tolerance, liver, cytochrome, biotransformation}

\section{Słowa kluczowe: salidrozyd, Rhodiola rosea, Rhodiola kirilowii, tolerancja alkoholu, watroba, cy- tochrom, biotransformacja}

\section{INTRODUCTION}

Alcoholism is a chronic civilization disease that generates serious socioeconomic consequences [1]. Due to the relatively small number of drugs currently prescribed as first-line drugs in its pharmacotherapy (mostly: disulfiram, acamprosate, naltrexone, and recently nalmefene [1-4]), the need for their long-term use in relation to the expected results $[2,4,5]$ and the occurrence of side effects [6], it has been increasingly emphasized that new directions in pharmacotherapy are still being required.

Over the past two decades at least, the development of studies aiming in the search for active metabolites and plant extracts, and thus effective phytotherapy of alcohol-used disorders, or their supportive therapy with the use of plant origin preparations (as herbal remedies), has been noticeable, especially in Asian, Middle East and African countries [7-10].

In recent years, the potential of inhibiting the development of alcohol tolerance by Rhodiola rosea L. (RR) and Rhodiola kirilowii (Regel) Maxim (RK) root extracts [11] and the key active metabolite contained in these extracts - salidroside (Sal) [12], belonging to the representatives of phenylethanoid glycosides [13], has been demonstrated. In the course of these studies, the inhibition of the development of tolerance to hypothermic and sedative effects of ethanol in RR-treated rats [11] as well as in Sal-administered rodents $(45 \mathrm{mg} / \mathrm{kg}$ b. w.; p.o.) was observed, which, in both cases, was accompanied by an increase in the peripheral level of ethanol $[11,12]$. These observations gave rise to the assumption that this compound may potentially have an inhibitory effect on the metabolic level. Until now, the results of a relatively small number of in vivo studies covering aspects of identification of the presence in various tissues and biological fluids (e.g. in plasma) of bioactive metabolites characteristic for representatives of the Crassulaceae family have been published, mainly mentioned phenylethanoids (to whom Sal and its aglycone - $p$-tyrosol (Tyr) belong), and to a much lesser extent phenylpropanoids. However, there is a noticeable increase in interest in studies on the use of extracts of Rhodiola sp. and their active substances, especially Sal and Tyr, in terms of the evaluation of their presence or in several animal organs, including the liver [14-20].

From the active molecules detected in the roots of RR and RK, in two studies it was indicated that Sal and kaempferol are capable of negatively inhibiting the expression of cytochrome 2E1 (CYP2E1) gene, encoding an enzyme crucial for the hepatic ethanol metabolism. Sal (administered p.o.) was investigated in a non-alcoholic steatohepatitis model in male Sprague Dawley rats [21], while kaempferol in an experimental model of alcoholic liver damage mice [22]. In one in vitro experiment focusing on the potential influence of salidroside on the activity of particular CYP enzyme isoforms, the inhibition of commercial RR extract products (containing rosavin, rosarine, Tyr and Sal) in relation to the activity of the cytochromes CYP3A4, CYP2D6, CYP1A2 was investigated and the ability of Sal to modulate the activity of these enzymes to an extent similar to the values observed for the corresponding synthetic, selective inhibitors [23]. In another in vitro study, in the presence of Sal, changes in pharmacokinetic profile of a cocktail composed of five different drugs dedicated to specific cytochrome isoforms (CYP1A2, CYP2B6, CYP2C9, CYP2D6, CYP3A4) and their activities were observed [24]. None of the above-cited studies focused on identifying potential changes to any form of cytochrome activity that might be related to the metabolism of Sal as such.

Considering the above, the aim of the study was to estimate a selected aspects of salidroside metabolism in the liver tissue in rats with induced alcohol tolerance. The goal was achieved by assessing changes in the transcription profile of genes encoding individual cytochrome P450 enzymes responsible for the metabolism of most ring compounds with strong antioxidant properties of the xenobiotics, in particular those representatives mentioned above, i.e. those initially demonstrated to be potentially responsible for the differential metabolism of studied xenobiotics under the influence of Sal [23, 24]: CYP1A2, 2D2 (human 
CYP2D6 equivalent), 3A1 (human CYP3A4 equivalent), 2C23 (human CYP2C9 equivalent). None of the above-cited studies investigated the aspects of profiling the expression of these genes in liver tissue in animals with induced ethanol tolerance. Understanding this aspect - evaluation of quantitative changes at the mRNA level of these genes may be a significant added value in better understanding the peripheral action of Sal in the experimental model mentioned.

\section{MATERIALS AND METHODS}

\section{Biological samples origin}

The material for the study was the livers of rats obtained during recent experiment conducted at the Department of Pharmacology (Poznań University of Medical Sciences) on male rats of the Wistar strain (body weight $309 \pm 3 \mathrm{~g}$ ), in which the development of alcohol tolerance was induced within nine days. In the course of the experiment, rats were divided into 6 groups and administered intraperitoneally (i.p.) with ethanol (water in control animals) and the active substance, Sal, orally (p.o.) using sterile metal intragastric probe in two doses: $4.5 \mathrm{mg} / \mathrm{kg}$ b.w. and $45 \mathrm{mg} / \mathrm{kg}$ b.w., respectively (control animals with methylcellulose). The experimental setup and dosing schedule of the substances are presented in the table below (tab. 1). The experiment was approved by the Local Ethics Committee for Animal Experiments (consent number: 87/2015). A detailed description of the in vivo experiment was previously described by Szulc et al. [12]. After completion of the experiment, the right hepatic lobe was removed from each animal immediately after decapitation and secured in liquid nitrogen for molecular analysis.

\section{RNA isolation, reverse transcription and QPCR reaction conditions}

Total RNA isolation from the rat hepatic tissue homogenates was carried out using Tri RNA Extraction Reagent (GenoPlast Biochemicals, Poland) according to the manufacturer's protocol using a modified Chomczynski and Sacchi method [25]. Isolated total RNA ( $500 \mathrm{ng} / \mu \mathrm{l}$ ) was used for reverse transcription and cDNA was synthesized according to the manufacturer's using iScript cDNA Synthesis Kit (Bio-Rad, USA). A relative, two-step quantitative real-time PCR (rt-qPCR; syn qRT-PCR) method was applied for the evaluation of mRNA levels changes for genes of interest (GOI). For that purpose, a set of housekeeping (HSK) genes were evaluated as potential reference genes in order to select the quantitatively most stable one. Following HSKs were screened as suitable reference genes for normalization of quantitative data obtained from qPCR quantification studies of these rodent samples: PBGD - encoding porphobilinogen deaminase, ACTB - encoding $\beta$-actin; GAPDH encoding glyceraldehyde-3-phosphate dehydrogenase, B2M - encoding $\beta$-2-microglobulin, and one candidate gene for the reference gene category - ALDH2 - encoding the type 2 aldehyde dehydrogenase.

A relative, two-step qRT-PCR method was applied for the evaluation of mRNA levels changes for: CYP1A2 - the gene coding for cytochrome 1A2; CYP2D2 - the gene coding for cytochrome 2D2; CYP3A1 - the gene coding for cytochrome

Table 1.

Division of animals into experimental groups taking into account the administered reagents

\begin{tabular}{|c|c|c|c|c|c|c|c|}
\hline $\begin{array}{l}\text { Group } \\
\text { number }\end{array}$ & Group name & $\mathrm{n}$ & $0.5 \% \mathrm{MC}($ p.o. $)$ & Sal4.5 (p.o.) & Sal45 (p.o.) & $\mathrm{H}_{2} \mathrm{O}$ (i.p.) & EtOH (i.p.) \\
\hline 1 & $\mathrm{H}_{2} \mathrm{O}+\mathrm{MC}$ & 8 & + & & & + & \\
\hline 2 & $\mathrm{EtOH}+\mathrm{MC}$ & 9 & + & & & & + \\
\hline 3 & $\mathrm{H}_{2} \mathrm{O}+\mathrm{Sal} \_4.5$ & 6 & & + & & + & \\
\hline 4 & EtOH+Sal_4.5 & 10 & & + & & & + \\
\hline 5 & $\mathrm{H}_{2} \mathrm{O}+\mathrm{Sal} \_45$ & 7 & & & + & + & \\
\hline 6 & EtOH+Sal_45 & 10 & & & + & & + \\
\hline
\end{tabular}

$\mathrm{n}$ - number of rats in each group; p.o. - intragastric route of administration; i.p. - intraperitoneal route of administration; Sal - salidroside; MC ( $p . o$.) - 0.5\% methylcellulose p.o. at complementary volume; EtOH i.p. - 30\% (v/v) ethanol at the dose of $3 \mathrm{~g} / \mathrm{kg} \mathrm{b.w;} \mathrm{H}_{2} \mathrm{O}$ i.p. - water i.p. at complementary volume; Sal_4.5 (p.o.) - salidroside p.o. at a dose of $4.5 \mathrm{mg} / \mathrm{kg}$ b.w; Sal_ 45 (p.o.) - salidroside p.o. at a dose of $45 \mathrm{mg} / \mathrm{kg}$ b.w; 
3A1 (equivalent to human CYP3A4); CYP2C23 gene coding for cytochrome 2C23 (equivalent to human CYP2C9), respectively. Primers sequences for analysed genes were designed and customdesigned using the Oligo 6.0 software (National Biosciences), their sequences are shown in table 2. A pair of primers dedicated to the amplification of mRNA for the mentioned CYP2E1 gene has been commercially ordered and designed by the manufacturer (Bio-Rad, Hercules, CA, USA) - PrimePCR SYBR Green Assay: CYP2E1; cat No. qRnoCID0003497. The reaction was carried out in a volume of $10 \mu \mathrm{l}$ according to manufacturer's instructions using a SsoAdvanced Universal SYBR Green Supermix kit (Bio-Rad, USA). Reaction mixture compositions were as follows: $3.5 \mu$ l RNA free water, $0.5 \mu \mathrm{lmix}$ of starter forward and reverse (final conc. $0.5 \mu \mathrm{M}$ of both), $5 \mu \mathrm{l}$ Sso, Advanced Universal SYBR Green Supermix, $1 \mu \mathrm{l}$ cDNA. Reaction conditions for all molecular targets are shown in table 3. Reading the increase in fluorescence at each cycle of the PCR reaction was performed at the elongation stage. For each quantified gene, standard curves were prepared from cDNA dilutions and generated from a minimum of five data points. The PCR reactions were carried out using MIC qPCR thermocycler (Biomolecular Systems, Australia). All experiments were at least repeated for three times. The data were evaluated using the micPCR software v.2.8.10 (Biomolecular Systems, Australia) with use of the REST algorithm incorporated to the micPCR software [26].

\section{Statistical analysis}

Statistical significance for the obtained numerical values of the results was assessed using the

Table 2.

Sequences of primers used for the qRT-PCR analysis

\begin{tabular}{ccc}
\hline Gene & Oligonucleotide sequence Forward $\left(5^{\prime} \rightarrow 3^{\prime}\right)$ & Oligonucleotide sequence Reverse $\left(3^{\prime} \rightarrow 5^{\prime}\right)$ \\
\hline CYP1A2 & CATCTTTGGAGCTGGATTTG & CCATTCAGTGAGGTGTCC \\
\hline CYP2D2 & TGAGTGGCGAGAGCAGAG & CGAGCATAAACAAGGGAGG \\
\hline CYP3A1 & CCCAGCTAGAGGGACAACAC & CGGGTCCCAAATCCGTAGAG \\
\hline CYP2C23 & CCGATGCTGTCTTCCGTCAT & GGGCCAAACTCTCACCAACA \\
\hline GAPDH & GATGGTGAAGGTCGGTGTG & ATGAAGGGGTCGTTGATGG \\
\hline PBGD & TCCTGAAACTCTGCTTCGCT & ACAGTTGCCCATCCTTCATC \\
\hline B2M & GTGCTTAGCAGCCTAGCAGT & GATGAAAACCGCACACAGGC \\
\hline ACTB & AAGTCCCTCACCCTCCCAAAAG & AAGCAATGCTGTCACCTTCCC \\
\hline ALDH2 & CAGCTACACCCGCCACGAGC & GCGGTAGGGCCGAATCCAGG
\end{tabular}

Table 3.

Steps and conditions of the rt-qPCR reaction for individual genes

\begin{tabular}{|c|c|c|c|c|c|c|}
\hline Step & & CYP1A2 & CYP2D2 & $\begin{array}{l}\text { CYP2C23 } \\
\text { CYP3A1 } \\
\text { CYP2E1 }\end{array}$ & ALDH2 & $\begin{array}{c}\text { GAPDH } \\
\text { PBGD } \\
\text { B2M } \\
\text { ACTB }\end{array}$ \\
\hline Initial denaturation & & $2 \mathrm{~min}, 95^{\circ} \mathrm{C}$ & $2 \mathrm{~min}, 95^{\circ} \mathrm{C}$ & $2 \mathrm{~min}, 95^{\circ} \mathrm{C}$ & $2 \min , 95^{\circ} \mathrm{C}$ & $2 \mathrm{~min}, 95^{\circ} \mathrm{C}$ \\
\hline \multirow{2}{*}{ Pre-cycling } & denaturation & $5 \mathrm{~s}, 95^{\circ} \mathrm{C}$ & $5 \mathrm{~s}, 95^{\circ} \mathrm{C}$ & $5 \mathrm{~s}, 95^{\circ} \mathrm{C}$ & $5 \mathrm{~s}, 95^{\circ} \mathrm{C}$ & $5 \mathrm{~s}, 95^{\circ} \mathrm{C}$ \\
\hline & elongation & $30 \mathrm{~s}, 58^{\circ} \mathrm{C}$ & $30 \mathrm{~s}, 58^{\circ} \mathrm{C}$ & $30 \mathrm{~s}, 58^{\circ} \mathrm{C}$ & $30 \mathrm{~s}, 58^{\circ} \mathrm{C}$ & $30 \mathrm{~s}, 58^{\circ} \mathrm{C}$ \\
\hline \multirow{2}{*}{ Cycling } & denaturation & $5 \mathrm{~s}, 95^{\circ} \mathrm{C}$ & $5 \mathrm{~s}, 95^{\circ} \mathrm{C}$ & $5 \mathrm{~s}, 95^{\circ} \mathrm{C}$ & $5 \mathrm{~s}, 95^{\circ} \mathrm{C}$ & $5 \mathrm{~s}, 95^{\circ} \mathrm{C}$ \\
\hline & elongation & $30 \mathrm{~s}, 58^{\circ} \mathrm{C}$ & $30 \mathrm{~s}, 58^{\circ} \mathrm{C}$ & $30 \mathrm{~s}, 58^{\circ} \mathrm{C}$ & $30 \mathrm{~s}, 59^{\circ} \mathrm{C}$ & $30 \mathrm{~s}, 58^{\circ} \mathrm{C}$ \\
\hline \multirow{2}{*}{$\begin{array}{l}\text { Melt (melting of } \\
\text { amplification products) }\end{array}$} & denaturation & $72-95^{\circ} \mathrm{C}$ & $72-95^{\circ} \mathrm{C}$ & $72-95^{\circ} \mathrm{C}$ & $72-95^{\circ} \mathrm{C}$ & $72-95^{\circ} \mathrm{C}$ \\
\hline & ramp & $0.3^{\circ} \mathrm{C} / \mathrm{s}$ & $0.3^{\circ} \mathrm{C} / \mathrm{s}$ & $0.3^{\circ} \mathrm{C} / \mathrm{s}$ & $0.3^{\circ} \mathrm{C} / \mathrm{s}$ & $0.3^{\circ} \mathrm{C} / \mathrm{s}$ \\
\hline Cycler number & & 28 & 25 & 30 & 35 & 35 \\
\hline
\end{tabular}




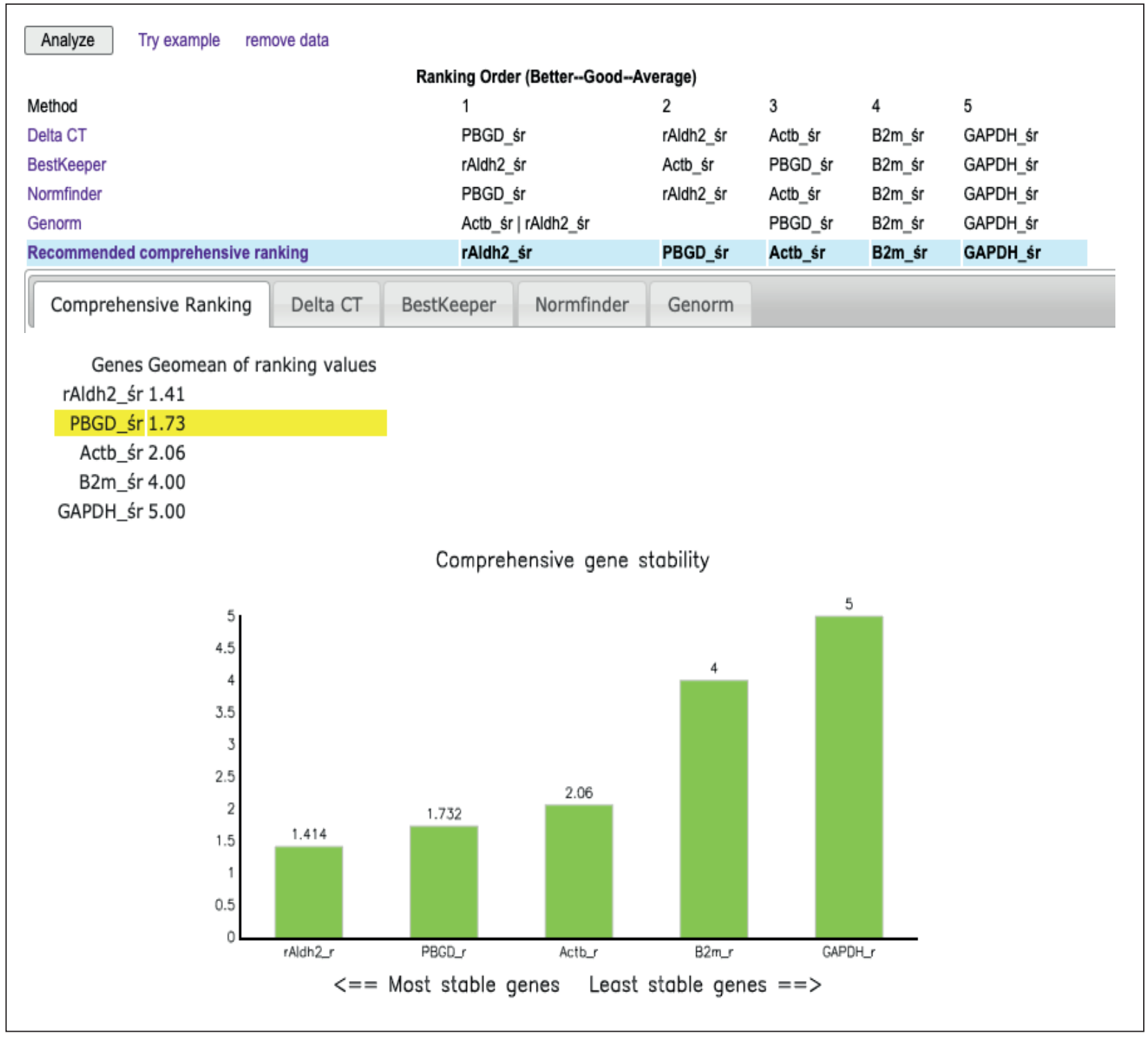

Figure 1.

Analysis of the usefulness of individual reference gene using the RefFinder software [online; login date 18/05/ 2021]

The figure shows the data for the mean values of Cq results (values in set of triplicated qPCR reactions) of each analysed gene (ALDH2, PBGD, ACTB, B2M, GAPDH, respectively) for all samples previously taken from the Excel spreadsheet, marked as follows: rALDH2_śr, PBGD_śr, ACTB_śr, B2M_śr, GAPDH_śr)

Statistica 13 software. The obtained results in individual groups were averaged, and then the SEM (standard error of the mean) was calculated for them. In order to verify the statistical significance of the discussed results, the ANOVA test was used with the level of significance $p \leq 0.05$. The Least Significant Difference test (Fisher's post-hoc test) was used to calculate the differences between the studied groups. The usefulness of using these reference genes was assessed using statistical methods as above and the free online
RefFinder software (https://www.heartcure.com. $\mathrm{au} / \mathrm{reffinder}$ ? type $=$ reference; login date: May 18 , 2021). The presented values in figures 2 and 3 were the result of a mathematical operation involving the division of raw results for each GOI / reference (ALDH2) gene, performed for each of the studied groups and were presented as mean \pm SEM. The reference point for all graphs was the reference sample (pooled cDNAmix sample), for which the found level of each of the analysed transcripts was assigned the value $=1$. 


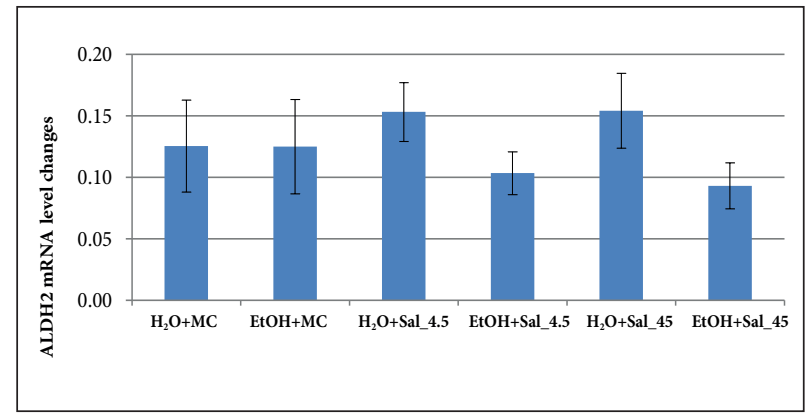

a

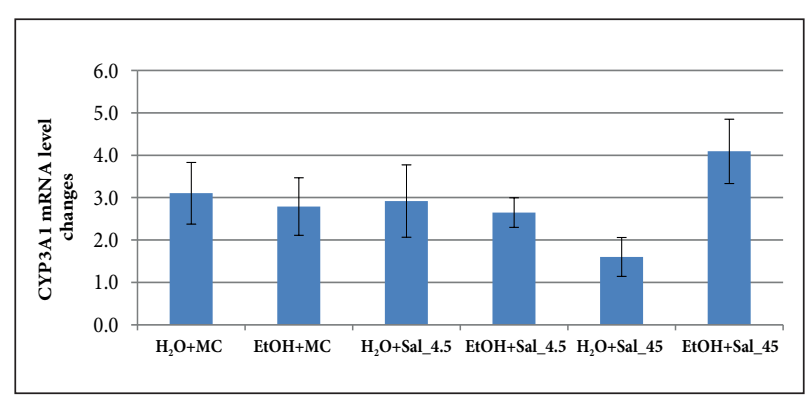

b

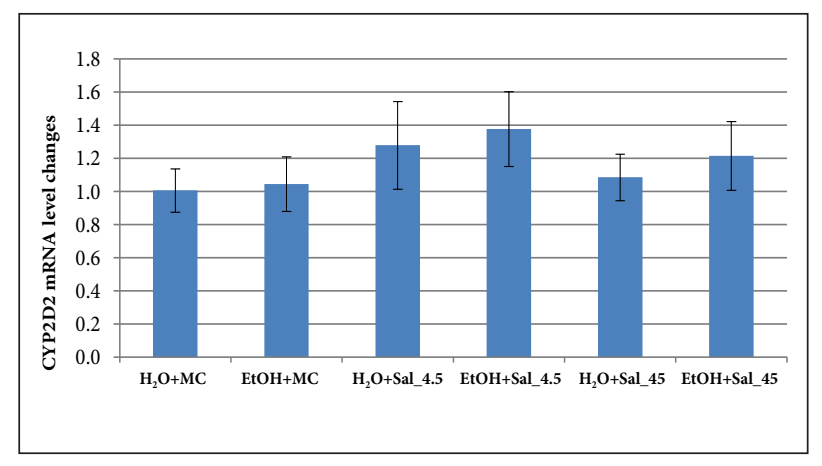

c

Figure 2.

Changes in the level of tested transcripts $(a-c)$ in the liver tissue sections from individual groups of rats: (a) mRNA level changes for ALDH2 encoding gene; (b) mRNA level changes for CYP3A1 encoding gene; (c) mRNA level changes for CYP2D2 encoding gene. All presented data were statistically insignificant (one-way ANOVA test)

$\mathrm{H}_{2} \mathrm{O}+\mathrm{MC}$ - animals receiving $\mathrm{H}_{2} \mathrm{O}$ and $0.5 \%$ methylcellulose (MC) p.o. at complementary volume; $\mathrm{EtOH}+\mathrm{MC}$ - animals receiving 30\% $(v / v)$ ethanol at the dose of $3 \mathrm{~g} / \mathrm{kg}$ b.w. (i.p.) and $0.5 \%$ methylcellulose (MC) (p.o.) at complementary volume; $\mathrm{H}_{2} \mathrm{O}+\mathrm{Sal} \_4.5 /$ $\mathrm{H}_{2} \mathrm{O}+\mathrm{Sal} \_45$ - animals receiving $\mathrm{H}_{2} \mathrm{O}$ at complementary volume and Sal at doses of $4.5 ; 45 \mathrm{mg} / \mathrm{kg}$ b.w. (p.o.), respectively; EtOH+Sal_4.5 / EtOH+Sal_45 animals administered with $\mathrm{EtOH}$ (as mentioned earlier) and Sal at doses of $4.5 ; 45 \mathrm{mg} / \mathrm{kg}$ b.w. (p.o.), respectively

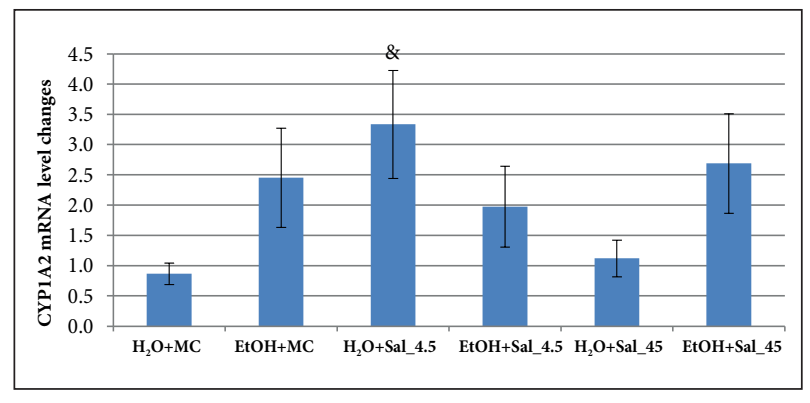

a

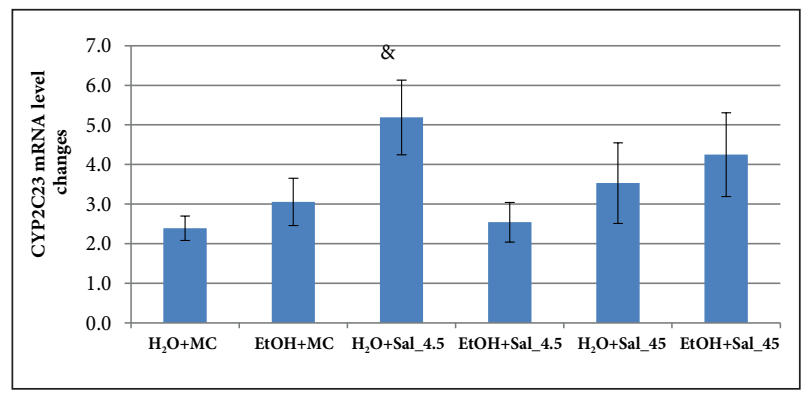

b

Figure 3.

Changes in the mRNA levels of (a) CYP1A2 and (b) CYP2C23 in the liver tissue sections from individual groups of rats. Asterisks indicate statistical significance (one-way ANOVA followed Least Significant Difference post hoc test). \& - vs. $\mathrm{H}_{2} \mathrm{O}+\mathrm{MC}(p<0.01)$

$\mathrm{H}_{2} \mathrm{O}+\mathrm{MC}-$ animals receiving $\mathrm{H}_{2} \mathrm{O}$ and $0.5 \%$ methylcellulose (MC) p.o. at complementary volume; $\mathrm{EtOH}+\mathrm{MC}$ - animals receiving $30 \%(\mathrm{v} / \mathrm{v})$ ethanol at the dose of $3 \mathrm{~g} / \mathrm{kg}$ b.w. (i.p.) and $0.5 \%$ methylcellulose (MC) (p.o.) at complementary volume; $\mathrm{H}_{2} \mathrm{O}+\mathrm{Sal} \_4.5 / \mathrm{H}_{2} \mathrm{O}+\mathrm{Sal} \_45$ - animals receiving $\mathrm{H}_{2} \mathrm{O}$ at complementary volume and $\mathrm{Sal}$ at doses of 4.5; $45 \mathrm{mg} / \mathrm{kg}$ b.w. (p.o.), respectively; EtOH+Sal_4.5/ EtOH+Sal_45 - animals administered with EtOH (as mentioned earlier) and Sal at doses of $4.5 ; 45 \mathrm{mg} / \mathrm{kg}$ b.w. (p.o.), respectively

\section{RESULTS}

\section{Strategy of selection of reference genes and sta- tistical normalization of the obtained results}

For all the reference genes tested: GAPDH, PBGD, B2M, statistically significant intergroup variability was observed: ANOVA: current effect: $\mathrm{F}(5,44)=4.50$, $p=0.0021$; ANOVA: current effect: $\mathrm{F}(5,44)=3.71$, $p=0.0069$; ANOVA: current effect: $\mathrm{F}(5,44)=2.30$, $p=0.0606$; ANOVA: $\mathrm{F}(5,44)=3.73, p=0.0067$, respectively. For Actb, poor statistical variability was also observed: ANOVA: current effect: $F(5,44)=1.90$, 
$p=0.1137$. Due to the failure of this part of the evaluation, which consisted in verifying the usefulness of standard reference genes, another attempt was made to select such a gene. For this purpose, the $\mathrm{ALDH} 2$ gene was proposed as a potential candidate for the verification procedure. For this gene, the intergroup variability was not statistically significant (ANOVA: current effect: $\mathrm{F}(5,43)=0.72, p=0.6147)$.

\section{Verification of validity of use of analysed refe- rence genes with the use of the RefFinder algo- rithm}

In order to verify the demonstrated relative stability of the expression at the mRNA level for the ALDH2 gene, the analysis of the results for the $\mathrm{Cq}$ (crossing point) values read directly from the MIC thermocycler for each of the amplification repeats of each primer pair for all analysed reference genes was also used. For this purpose, the free online software was used - RefFinder (https://www.heartcure. com.au/reffinder/?type=reference; login date: May $18,2021)$. After placing the data for the mean values of $\mathrm{Cq}$ (values in set of studies genes, marked as follows: rALDH2_śr, PBGD_śr, ACTB_śr, B2M_śr, GAPDH_śr) for all samples previously taken from the Excel spreadsheet, a graphical representation of the coefficient of variation of the studied genes was obtained (fig. 1). The variability of Cq mean values between groups indicated the value of the coefficient of variation of the ALDH2 gene (fig. 2a) as equal to 1.414 - which clearly pointed it as the least variable and thus the most stable in the analysed population of samples and possible to be used as a reference gene for relative GOIs expression evaluation at the mRNA level in the planned experimental setup.

\section{Assessment of transcript level changes for GOIs}

In order to normalize the results obtained from quantitative analyses of all studied GOIs, the ALDH2 gene was adopted as the reference gene (fig. 2a). From each analyse, the values read from the MIC thermocycler, after normalizing the data with respect to previously generated standard curves (the so-called Pfaffl method) [26, 27], were averaged and then divided by the mean values of results for the ALDH2 gene for each sample within each group. Thus, obtained values were processed statistically, according to the methodology described above.
There was no statistically significant variation between groups for the CYP3A1 gene (ANOVA: current effect: $F(5,43)=1.41, p=0.2395)$ (fig. 2b). The analyses of individual study groups showed only a slight, yet statistically insignificant decrease in mRNA level in the $\mathrm{EtOH}+\mathrm{MC}$ group, as compared to the $\mathrm{H}_{2} \mathrm{O}+\mathrm{MC}$ control group. In the case of ethanol groups, detected slight fluctuations in the level of the CYP3A1 transcripts (a decrease in the EtOH+Sal_4.5 group vs. an increase in EtOH+Sal_45, respectively), compared to the corresponding control EtOH+MC group, were also statistically insignificant. Comparing the ethanol groups administered with Sal in two doses $\left(\mathrm{EtOH}+\mathrm{Sal} \_4.5\right.$ and EtOH+Sal_45 groups, respectively) - the dose-dependence effect correlated with the increase in mRNA level was visible only in the group with its higher dose (EtOH+Sal_45), however, this difference was not statistically significant.

For the CYP2D2 gene, also no statistically significant differences were observed between the groups (ANOVA: current effect: $\mathrm{F}(5,43)=0.561, p=0.7288$ ) (fig. 2c). Further analyses showed a statistically insignificant increase in the mRNA level in the $\mathrm{EtOH}+\mathrm{MC}$ group $v s$. control group $\mathrm{H}_{2} \mathrm{O}+\mathrm{MC}$. A similar trend, not showing statistical significance, was found in the groups of ethanol-induced rats. Here, also the induction of transcription in both $\mathrm{EtOH}$ groups: $\mathrm{EtOH}+\mathrm{Sal} \_4.5$ and EtOH+Sal_45 was observed, as compared with corresponding EtOH+MC control. In the ethanol-induced group, but influenced with lower ethanol dose (EtOH+Sal_4.5 group), the observed increase in mRNA level (compared to EtOH+Sal_45 group) was statistically irrelevant. The comparison of differences between the EtOH+Sal_4.5 and EtOH+Sal_45 groups also did not show statistical significance, although the EtOH+Sal_4.5 group was characterized by a higher level of transcripts.

In the case of the CYP1A2 gene, also, in general, there was no statistically significant variation between groups (ANOVA: current effect: F $(5,43)=1.54, p=0.1971$ ) (fig. 3a). An almost 3-fold increase in the level of transcripts in the group receiving ethanol alone $(\mathrm{EtOH}+\mathrm{MC})$, as compared to the group devoid of alcohol influence $\left(\mathrm{H}_{2} \mathrm{O}+\mathrm{MC}\right)$ was detected. However, it was a statistically insignificant relationship. A statistically significant increase in the mRNA level was observed only in the $\mathrm{H}_{2} \mathrm{O}+\mathrm{Sal} \_4.5$ group, as compared to control group $\left(\mathrm{H}_{2} \mathrm{O}+\mathrm{MC}\right) ; p<0.01$, without a statistical significance in the case of animals receiving a higher dose $\left(\mathrm{H}_{2} \mathrm{O}+\mathrm{Sal} \_45\right)$. When it comes to comparing these 
two groups it can be noted that despite a nearly threefold decrease in the level of CYP1A2 transcripts in the $\mathrm{H}_{2} \mathrm{O}+\mathrm{Sal} \_45$ group compared to the group with a lower Sal dose $\left(\mathrm{H}_{2} \mathrm{O}+\mathrm{Sal} \_4.5\right)$, this variability also did not show statistical significance due to the large error value.

For the evaluated CYP2C23 gene, no intergroup variability was observed (ANOVA: current effect: $\mathrm{F}(5,43)=1.74, p=0.1459$ ) (fig. 3b). However, further detailed analysis showed that in the groups under the influence of Sal - $\left(\mathrm{H}_{2} \mathrm{O}+\mathrm{Sal} \_4.5\right.$ and $\left.\mathrm{H}_{2} \mathrm{O}+\mathrm{Sal} \_45\right)$ - there was an increase in the mRNA level $v s$. the control group $\left(\mathrm{H}_{2} \mathrm{O}+\mathrm{MC}\right)$, statistically significant in the $\mathrm{H}_{2} \mathrm{O}+\mathrm{Sal} \_4.5$ group $(p<0.01)$. When analysing the ethanol groups of animals influenced with both doses of Sal, a slight decrease in the mRNA level was observed in the EtOH+Sal_4.5 group, and conversely an increase in the EtOH+Sal_45 group, in comparison with the corresponding control EtOH+MC group, however, these differences were statistically insignificant.

\section{DISCUSSION}

For the purpose of the study, the selection of molecular targets was based primarily on the results of two reports [23, 24], in which commercial extracts of RR [23] or Sal [24] were administered to an enzymes cocktail containing three [23] or five human cytochromes [24] - in the presence of selective inhibitors - xenobiotics currently used in pharmacotherapy, then the time shifts in the formation of their individual metabolites were measured. As previously mentioned, these studies demonstrated the ability of RR or Sal to modulate the activity of these enzymes to a degree similar to the values observed for the corresponding synthetic, selective inhibitors [23]. In the study by Thu et al. [23], changes in the activity of individual cytochromes (CYP3A4, CYP2D6, CYP1A2) were measured using high performance liquid chromatography (HPLC) technique by analysing the change in the rate of formation of the above-mentioned metabolites drugs (ketoconazole, quinidine and $\beta$-naphthoflavone, respectively) correlated with the concentrations of RR extracts used (values expressed as pmol metabolite/pmol enzyme/min). All studied RR preparations showed the ability to inhibit all CYP enzymes, but to a very different degree depending on the analysed extract, with more than 20 -fold difference in their total CYP inhibitory potential. The RR tincture formulation was the strongest inhibitor giving the lowest
$\mathrm{IC}_{50}$ values of $7.2 \pm 0.7,13 \pm 1.7$ and $10.7 \pm 5.6 \mu \mathrm{g} / \mathrm{ml}$, respectively. CYP3A4 was inhibited to the greatest extent. The authors explain the significant variability of the inhibitory potential by, inter alia, the fact that these products had different manufacturers, country of origin, and were characterized by a different form and composition [23]. Wei et al. [24] showed a similar inhibition of in vivo activity of CYP1A2, CYP3A4, CYP2C9, CYP2B6, with the exception of CYP2D6, due to, among others, Sal, also with the use of reference inhibitors (other than in the study by Thu et al. [23]: phenacetin, midazolam, losartan, bupropion, metoprolol, respectively). In this study, Sal (30 mg/kg p.o.) was used and the animals were administered either only once or once a day for 7 days. For the contrary to the previous experiment, in this case the concentrations of non-derivatives of these synthetic xenobiotics were measured in the serum of animals using ultra performance liquid chromatography (UPLC), and the same, in the presence or absence of Sal, and on this basis changes in their pharmacokinetic profile were determined [24].

None of the studies reported directly measured the change in biochemical cytochrome activity in rat liver tissues under the influence of Sal. What is more, these analyses were not performed in the experimental model on rodents under the influence of ethanol. Only results indirectly demonstrating the inhibition of the activity of the investigated enzymes were observed (measurement of changes in the concentrations of reference drugs or of the drugs themselves).

As previously mentioned, in this study the analysis of changes in the molecular activity of cytochromes (CYP3A1, CYP2D2, CYP1A2, CYP2C23) was performed on research material obtained also from an in vivo experiment, but carried out in a different scheme and from a different type of biological material than in the study by Wei et al. [24]. In our investigation, the subject of analyses were sections of the right hepatic lobe from rats receiving Sal in two different doses $(4.5 \mathrm{mg} / \mathrm{kg}$ b.w. and $45 \mathrm{mg} / \mathrm{kg}$ b.w., p.o.), which induced tolerance to the presence of a high dose of ethanol [12]. Also, in relation to the above-mentioned two studies, an attempt was made to almost directly measure the change in the molecular activities of CYPs under the influence of Sal and EtOH using a different research technique - the quantitative PCR with real-time detection of changes in fluorescence gain. In the course of the study, for the majority of the obtained results, statistical significance was not usually found. Only in the case of CYP2D2 for both doses of Sal+EtOH there 
was a noticeable increase in the mRNA level for the gene of this enzyme, although, as mentioned, statistically insignificant, although the dose-dependence correlation was inversely proportional. For the remaining genes, the effects in the form of induction or inhibition of their transcription were usually opposite - surprisingly at a dose of $4.5 \mathrm{mg} / \mathrm{kg}$ b.w. there was an insignificant statistical reduction in the level of transcripts (for the CYP3A1, CYP1A2 and CYP2C23 gene), while at the higher dose $(45 \mathrm{mg} / \mathrm{kg}$ b.w.) there was a non - significant statistical increase, especially for the CYP3A1 gene, with no effect for the CYP1A2 one.

In the light of the current state of knowledge, it is very difficult to say unequivocally whether Sal has the ability to directly bind to the active centres of the abovementioned cytochromes. Up to date, there are no model studies, in particular in silico or crystallographic ones, that would describe exactly this possibility. Moreover, it cannot be ruled out that the observed different quantitative changes in the analysed transcripts under the influence of both doses of Sal + EtOH, mostly without statistical significance in relation to the control ethanol group $(\mathrm{EtOH}+\mathrm{MC})$ or in relation to each other $\left(\mathrm{EtOH}+\mathrm{Sal} \_45 v s\right.$. EtOH+Sal_4.5), may be at least in part a consequence of the dose-dependent effect of Sal on tissue - specific transcription factors regulating this stage of expression of the investigated genes in the liver of rats by the presence of a high dose of ethanol. At present, no transcription factor has been reported for above genes for which Sal could be a selective modulator. The possible validity of this assumption may, at least in part, be found in the results of studies which demonstrated the significant contribution of eukaryotic transcription factors in the regulation of the expression of genes encoding numerous cytochromes $[28,29]$, and their examples may be as follows: CAR (chimeric antigen receptor), PXR (pregnane X receptor ) factors - a potential modulators of the activity of cytochromes from the CYP3A subfamily (e.g. CYP3A23/1, CYP3A2) [3032], PPAR (peroxisome proliferator-activated receptor) [33-35], HNF4 (Hepatocyte nuclear factor 4 alpha ) factor as a regulator of CYP2D6 activity [28], FoxO (class $\mathrm{O}$ of forkhead-box transcription factor) or Nrf2 (nuclear factor erythroid 2-related factor 2) [34]. An important aspect is also the influence of the intracellular signalling pathway, in which they participate, among others: cytokines, hormones, and growth factors to specific isoforms of enzymes from the CYP family [32]. However, the identification of selective Sal-dependent transcription modulators of the studied cytochromes requires further in-depth molecular studies in this area.

According to the current state of knowledge, deglycosylation by $\beta$-glucosidases present in acellular extracts of the human small intestine and liver, leading to the hydrolysis of various types of phenolic glycosides, which are very often a component of the plant diet, and thus phenylethanoids, may play an important role in their absorption and metabolism [3638]. Most of the aglycons, which somehow "escape" metabolism in the small intestine, are metabolized not only by mentioned phase I but also by phase II biotransformation enzymes, including uridine diphosphate (UDP) - glucuronosyl transferases (leading to the formation of $\mathrm{O}$-glucuronides), $\mathrm{O}$-sulphategenerating sulfotransferases and catechol-O-methyltransferases leading to the formation of $\mathrm{O}$-methylated metabolites $[38,39]$. Thus, the quantitative representation of aglycons may be of a negligible nature in the peripheral circulatory system of the organism [40]. Therefore, the effects of non-selective changes in cytochrome activity may also be a consequence of the participation of the enzymatic components of phase II biotransformation of xenobiotics in the liver. This hypothesis is confirmed by one of the studies conducted in vivo on rats which received a single dose of Sal in a dose of $50 \mathrm{mg} / \mathrm{kg}$ b.w. (p.o.), which led to the identification of four of its seven metabolites in the form of their glucuronide and sulphate derivatives, characteristic of the second stage of biotransformation of xenobiotics [41]. In another study Sal was administered rats, i.g. in single doses: 100 or $500 \mathrm{mg} / \mathrm{kg}$ b.w. [42], therefore in different doses than in the experiment of Szulc et al. [12], from which the tested tissue material is derived. In the study by $\mathrm{Hu}$ et al., out of 8 identified metabolites, 7 of them were phase II biotransformation products [42]. Another example of the work of assessing the pharmacokinetic profile of Sal after a single administration of rats in two separate dosing schedules: $100 \mathrm{mg} / \mathrm{kg}$ b.w. (p.o.) and $50 \mathrm{mg} / \mathrm{kg}$ b.w. (i.v.) is a work by Guo et al. [40]. These results confirmed the observations found after a single administration of Sal only by the i.v. [43]. None of the above-mentioned studies have directly measured in vivo the biochemical or molecular change in enzymatic activities in the liver tissue of rodents, neither untreated, nor treated with ethanol. Explaining this scientific area requires further examinations.

An important aspect in considering different effect of both doses of Sal on the activity of the measured genes may be the potential participation of intestinal microbiota in the metabolism of phenylethanoids, including the studied Sal. To date, only a few studies 
indicating such a possibility have been published [4446]. In the study by Cui et al. after $36 \mathrm{~h}$ of incubation of another phenylethanoid representative - verbascoside in the intestinal fraction of human or rat with the Escherichia coli bacteria, the formation of 14 verbascoside derivatives was shown only in the presence of these bacteria [45]. Another example is an in vitro study in which the key components of endogenous Tyr, and Sal biosynthesis from plant glucose were genetically engineered into E. coli MG1655 strain, including: RR-derived UGT73B6 gene encoding the appropriate uracyl-glucosyl transferase, its two mutants: AroG $^{*}$ (responsible for the so-called anti-regression immunity) (replacement of Asp146 with Asn) [47] and TyrA* (feedback-resistant TyrA mutant), yeast gene ARO10 pyruvate decarboxylase, components of the L-tyrosine pathway (aroG, tyrA and aroL) [44], where it was proved that the presence of these enzymes is crucial for the proper course of the entire pathway of metabolism of these compounds and that E-strain bacteria $E$. coli are able to participate independently in the biosynthesis and biotransformation of these phenylglycoside active substances [44]. Again, none of the above experiments were performed directly in the tissue material in vivo or with the use of intestinal scrapings taken directly from the animals. There are also any experiments carried out in this field under the influence of any dose of ethanol. The changes in the molecular activity of these enzymes were also not directly measured $[45,46]$, chromatographic techniques were used for analytical measurements, e.g. UPLC-Q-TOFMS [45]. In the light of the cited evidence, one can only indicate the participation of the intestinal flora in the final fate of Sal in the organism of the studied animals as highly probable.

\section{CONCLUSION}

A statistically significant increase in the mRNA level was observed only in the case of CYP1A2 gene in the group $\mathrm{H}_{2} \mathrm{O}+\mathrm{Sal} \_4.5 v s$. control group $\left(\mathrm{H}_{2} \mathrm{O}+\right.$ $\mathrm{MC})(p<0.01)$. There was no unequivocal effect of salidroside on the transcription of investigated cytochrome genes in the liver of rats with induced alcohol tolerance.

\section{ACKNOWLEDGEMENTS}

This study has been supported by financial resources earmarked for statutory research of the Department of Pharmacology (Poznań University of Medical
Sciences) and Institute of Natural Fibres and Medicinal Plants National Research Institute in Poznań. All the authors performed and prepared the manuscript draft, data gathering, and interpreted the findings.

Conflict of interest: Authors declare no conflict of interest.

\section{REFERENCES}

1. Xuan Z, Naimi TS, Kaplan MS, Bagge CL, Few LR, Maisto $S$ et al. Alcohol policies and suicide: A review of the literature. Alcohol Clin Exp Res. 2016; 40(10):2043-205. doi: https://dx.doi. org/10.1111/acer.13203

2. Crowley P. Long-term drug treatment of patients with alcohol dependence. Aust Prescr 2015; 38(2):41-43. doi: https://dx.doi.org/10.18773/ austprescr.2015.015

3. Litten RZ, Wilford BB, Falk DE, Ryan ML, Fertig JB. Potential medications for the treatment of alcohol use disorder: An evaluation of clinical efficacy and safety. Subst Abus 2016; 37(2):286-98. doi: https://dx.doi.org/10.1080/08897077.2015.1 133472

4. Kim Y, Hack LM, Ahn ES, Kim J. Practical outpatient pharmacotherapy for alcohol use disorder. Drugs Context 2018; 7:212308. doi: https:// dx.doi.org/10.7573/dic.212308

5. Ehrie J, Hartwell EE, Morris PE, Mark TL, Kranzler HR. Survey of addiction specialists' use of medications to treat alcohol use disorder. Front Psychiatry 2020; 11:47. doi: https://dx.doi. org/10.3389/fpsyt.2020.00047

6. Kranzler HR, Soyka M. Diagnosis and pharmacotherapy of alcohol use disorder: A Review. JAMA 2018; 320(8):815-824. doi: https://dx.doi. org/10.1001/jama.2018.11406

7. Overstreet DH, Keung WM, Rezvani AH, Massi M, Lee DY. Herbal remedies for alcoholism: promises and possible pitfalls. Alcohol Clin Exp Res 2003; 27(2):177-85. doi: https://dx.doi. org/10.1097/01.ALC.0000051022.26489.CF

8. Rezvani AH, Overstreet DH, Perfumi M, Massi M. Plant derivatives in the treatment of alcohol dependency. Pharmacol Biochem Behav 2003; 
75(3):593-606. doi: https://dx.doi.org/10.1016/ S0091-3057(03)00124-2

9. Liu Q, Lawrence AJ, Liang J-H. Traditional Chinese medicine for treatment of alcoholism: from ancient to modern. Am J Chin Med 2011; 39(1):1-13. doi: https://dx.doi.org/10.1142/ S0192415X11008609

10. Ożarowski M, Mikołajczak PŁ, Thiem B. Medicinal plants in the phytotherapy of alcohol or nicotine addiction. Implication for plants in vitro cultures. Przegl Lek 2013; 70(10):869-74.

11. Szulc M, Mularczyk P, Grządzielski P, Zakowicz P, Kujawski R, Gryszczyńska A et al. Influence of extracts from Rhodiola rosea and Rhodiola kirilowii on the development of alcohol tolerance in rats. Herba Pol 2018 a; 64(4):34-43. doi: https://dx.doi. org/10.2478/hepo-2018-0021

12. Szulc M, Mularczyk P, Kujawski R, Gryszczyńska A, Kamińska E, Geppert B et al. Influence of salidroside, a neuroactive compound of Rhodiola rosea L., on alcohol tolerance development in rats. Herba Pol 2018 b; 64 (1): 22-35. doi: https:// dx.doi.org/10.2478/hepo-2018-0002

13. Xue Z, Yang B. Phenylethanoid glycosides: Research advances in their phytochemistry, pharmacological activity and pharmacokinetics. Molecules 2016; 21(8):991. doi: https://dx.doi. org/10.3390/molecules 21080991

14. Chang YW, Yao HT, Hsieh SH, Lu TJ, Yeh TK. Quantitative determination of salidroside in rat plasma by on-line solid-phase extraction integrated with high-performance liquid chromatography/electrospray ionization tandem mass spectrometry. J Chromatogr 2007; B;857(1):164169. doi: https://dx.doi.org/10.1016/j.jchromb. 2007.06.029

15. Zhang J, Chen XH, Wang P, Huo L, Shen ZD, Guo $\mathrm{XR}$ et al. LC-MS determination and pharmacokinetic study of salidroside in rat plasma after oral administration of traditional Chinese medicinal preparation Rhodiola crenulata extract. Chromatographia 2008; 67(9):695-700. doi: https:// dx.doi.org/10.1365/s10337-008-0585-7

16. Zhang Y, Li L, Lin L, Liu J, Zhang Z, Xu D et al. Pharmacokinetics, tissue distribution, and excretion of salidroside in rats. Planta Med
2013; 79(15):1429-1433. doi: https://dx.doi. org/10.1055/s-0033-1350807

17. Mao Y, Li Y, Yao N. Simultaneous determination of salidroside and tyrosol in extracts of Rhodiola L. by microwave assisted extraction and highperformance liquid chromatography. J Pharm Biomed Anal 2007a; 45(3):510-515. doi: https:// dx.doi.org/10.1016/j.jpba.2007.05.031

18. Mao Y, Zhang X, Zhang X, Lu G. Development of an HPLC method for the determination of salidroside in beagle dog plasma after administration of salidroside injection: application to a pharmacokinetics study. J Sep Sci 2007b; 30(18):3218-3222. doi: https://dx.doi.org/10.1002/jssc.200700273

19. Yu S, Liu L, Wen T, Liu Y, Wang D, He Y et al. Development and validation of a liquid chromatographic/electrospray ionization mass spectrometric method for the determination of salidroside in rat plasma: application to the pharmacokinetics study. J Chromatogr B 2008; 861(1):10-15. doi: https://dx.doi.org/10.1016/j.jchromb.2007.11.035

20. Chernysheva GA, Smolniakova VI, Cherkashina IV, Plotnikov MB, Tolstikova TG, Krysin AP et al. The main pharmacokinetic parameters of $p$-tyrosol upon intravenous injection in rats, Eksp Klin Farmakol 2005; 68(6):43-4.

21. Yang ZR, Wang HF, Zuo TC, Guan LL, Dai N. Salidroside alleviates oxidative stress in the liver with non-alcoholic steatohepatitis in rats. BMC Pharmacol Toxicol 2016; 17(1):1-6. doi: https:// dx.doi.org/10.1186/s40360-016-0059-8

22. Wang S, He H, Chen L, Zhang W, Zhang X, Chen J. Protective effects of salidroside in the MPTP/ MPP+-induced model of Parkinson's disease through ROS-NO-related mitochondrion pathway. Mol Neurobiol 2015; 51(2):718-728. doi: https://dx.doi.org/10.1007/s12035-014-8755-0

23. Thu OK, Nilsen OG, Hellum B. In vitro inhibition of cytochrome P-450 activities and quantification of constituents in a selection of commercial Rhodiola rosea products. Pharm Biol 2016; 54(12):3249-3256. doi: https://dx.doi.org/10.108 0/13880209.2016.1223145

24. Wei YL, Du HJ, Lin YP, Wu ML, Xu RA. Effects of salidroside on rat CYP enzymes by a cocktail of probe drugs. Iran J Basic Med Sci 2018; 
21(4):422. doi: https://dx.doi.org/10.22038/ IJBMS.2018.26106.6414

25. Chomczynski P, Sacchi N. Single-step method of RNA isolation by acid guanidinium thiocyanate-phenol-chloroform extraction. Anal Biochem 1987; 162(1):156-9. doi: https://dx.doi. org/10.1006/abio.1987.9999

26. Pfaffl MW, Horgan GW, Dempfle L. Relative expression software tool (REST $\odot$ ) for group-wise comparison and statistical analysis of relative expression results in real-time PCR. Nucleic Acids Res 2002; 30(9):e36-e36. doi: https://dx.doi. org/10.1093/nar/30.9.e36

27. Pfaffl MW. A new mathematical model for relative quantification in real-time RT-PCR. Nucleic Acids Res 2001; 29(9):e45-e45. doi: https://dx.doi. org/10.1093/nar/29.9.e45

28. Cairns W, Smith CD, McLaren AW, WolfCR. Characterization of the human cytochrome P4502D6 promoter: a potential role for antagonistic interactions between members of the nuclear receptor family. J Biol Chem 1996; 271(41):25269-25276. doi: https://dx.doi.org/10.1074/jbc.271.41.25269

29. Honkakoski P, Negishi M. Regulation of cytochrome P450 (CYP) genes by nuclear receptors. Biochem J 2000; 347(2):321-337. doi: https:// dx.doi.org/10.1042/bj3470321

30. Ni S, Wang X, Wang J, Zeng S, Zhao Z. Expression of CYP3A23/1, CYP3A2, PXR, CAR and HNF4 $\alpha$ in large-for-gestational-age neonatal rats. Pharmazie 2009; 64(4):252-257.

31. Yao R, Yasuoka A, Kamei A, Ushiama S, Kitagawa $\mathrm{Y}$, Rogi $\mathrm{T}$ et al. Nuclear receptor-mediated alleviation of alcoholic fatty liver by polyphenols contained in alcoholic beverages. PloS One 2014; 9(2):e87142. doi: https://dx.doi.org/10.1371/ journal.pone. 0087142

32. Daujat-Chavanieu M, Gerbal-Chaloin S. Regulation of CAR and PXR expression in health and disease cells 2020; 9(11):2395. doi: https://dx.doi. org/10.3390/cells9112395

33. Domínguez-Avila JA, González-Aguilar GA, Alvarez-Parrilla E, De la Rosa LA. Modulation of PPAR expression and activity in response to polyphenolic compounds in high fat diets. Int
J Mol Sci 2016; 17(7):1002. doi: https://dx.doi. org/10.3390/ijms17071002

34. Pallauf K, Duckstein N, Hasler M, Klotz LO, Rimbach G. Flavonoids as putative inducers of the transcription factors Nrf2, FoxO, and PPAR $\gamma$. Oxid Med Cell Longev 2017; 2017:4397340. doi: https://dx.doi.org/10.1155/2017/4397340

35. Rigano D, Sirignano C, Taglialatela-Scafati O. The potential of natural products for targeting PPAR $\alpha$. Acta Pharm Sin B 2017; 7(4):427-438. doi: https:// dx.doi.org/10.1016/j.apsb.2017.05.005

36. Németh K, Plumb G W, Berrin J G, Juge N, Jacob R, Naim H Y, Kroon PA. Deglycosylation by small intestinal epithelial cell $\beta$-glucosidases is a critical step in the absorption and metabolism of dietary flavonoid glycosides in humans. Eur J Nutr 2003; 42(1):29-42. doi: https://dx.doi. org/10.1007/s00394-003-0397-3

37. Day AJ, DuPont MS, Ridley S, Rhodes M, Rhodes MJ, Morgan MR et al. Deglycosylation of flavonoid and isoflavonoid glycosides by human small intestine and liver $\beta$-glucosidase activity. FEBS Letters 1998; 436(1):71-75. doi: https://dx.doi. org/10.1016/S0014-5793(98)01101-6

38. Day AJ, Williamson G. Biomarkers for exposure to dietary flavonoids: a review of the current evidence for identification of quercetin glycosides in plasma. Br J Nutr 2001; 86(S1):S105-S110. doi: https://dx.doi.org/10.1079/BJN2001342

39. SpencerJP. Metabolism of tea flavonoidsin thegastrointestinal tract. J Nutr 2003; 133(10):3255S3261S. doi: https://dx.doi.org/10.1093/jn/133. $10.3255 \mathrm{~S}$

40. Guo N, Zhu M, Han X, Sui D, Wang Y, Yang Q. The metabolism of salidroside to its aglycone $p$-tyrosol in rats following the administration of salidroside. PLoS One 2014; 9(8):e103648. doi: https://dx.doi.org/10.1371/journal.pone.0103648

41. Han F, Li Y, Mao X, Zhang X, Guan J, Song A et al. Metabolic profile of salidroside in rats using high-performance liquid chromatography combined with Fourier transform ion cyclotron resonance mass spectrometry. Anal Bioanal Chem 2015; 408(7):1975-1981. doi: https://dx.doi. org/10.1007/s00216-015-9080-9 
42. Hu Z, Wang Z, Liu Y, Wu Y, Han X, Zheng J et al. Metabolite profile of salidroside in rats by ultraperformance liquid chromatography coupled with quadrupole time-of-flight mass spectrometry and high-performance liquid chromatography coupled with quadrupole-linear ion trap mass spectrometry. J Agric Food Chem 2015; 63(41):8999-9005. doi: https://dx.doi. org/10.1021/acs.jafc.5b04510

43. Guo N, Hu Z, Fan X, Zheng J, Zhang D, Xu T et al. Simultaneous determination of salidroside and its aglycone metabolite $p$-tyrosol in rat plasma by liquid chromatography-tandem mass spectrometry. Molecules 2012; 17(4):4733-4754. doi: https://dx.doi.org/10.3390/molecules17044733

44. Bai Y, Bi H, Zhuang Y, Liu C, Cai T, Liu X et al. Production of salidroside in metabolically engineered Escherichia coli. Sci Rep 2014; 4(1):1-8. doi: https://dx.doi.org/10.1038/srep06640
45. Cui Q, Pan Y, Xu X, Zhang W, Wu X, Qu S et al. The metabolic profile of acteoside produced by human or rat intestinal bacteria or intestinal enzyme in vitro employed UPLC-Q-TOF-MS. Fitoterapia 2016; 109:67-74. doi: https://dx.doi. org/10.1016/j.fitote.2015.12.011

46. Luo Z, Ma X, Liu Y, Lu L, Yang R, Yu G et al. An approach to characterizing the complicated sequential metabolism of salidroside in rats. Molecules 2016; 21(6):706. doi: https://dx.doi. org/10.3390/molecules21060706

47. Kikuchi Y, Tsujimoto K, Kurahashi O. Mutational analysis of the feedback sites of phenylalanine-sensitive 3-deoxy-D-arabino-heptulosonate-7-phosphate synthase of Escherichia coli. Appl Environ Microbiol 1997; 63(2):761-762. doi: https:// dx.doi.org/10.1128/aem.63.2.761-762.1997 